\title{
Blueberry Splitting Tendencies as Predicted by Fruit Firmness
}

\author{
Donna A. Marshall ${ }^{1}$, James M. Spiers, and Stephen J. Stringer \\ Thad Cochran Southern Horticultural Laboratory, P.O. Box 287, 810 \\ Highway 26W, Poplarville, MS 39470 \\ Additional index words. fruit splitting, rabbiteye blueberry, southern highbush blueberry
}

\begin{abstract}
To improve the quality of berries during handling and shipping, blueberry breeders have strived to develop a fruit that is firm in texture. However, some previous studies have suggested that blueberry cultivars with firmer fruit were more susceptible to splitting. This study was conducted to further investigate the correlation between splitting susceptibility and fruit firmness. Various cultivars and selections of rabbiteye (Vaccinium ashei) and southern highbush (interspecific hybrids primarily consisting of $V$. corymbosum) blueberry were used to determine whether berries displaying higher fruit firmness also have a higher incidence of splitting. Three distinctly different measurements of berry firmness were obtained using two instruments: QTS25 and FirmTech2. Berries were subsequently submitted to laboratory procedures to induce splitting. In general, firmness measured as either deformation (FirmTech2) or modulus of elasticity (QTS25) correlated with splitting tendencies. There are exceptions, however, that need to be further examined.
\end{abstract}

Rabbiteye (Vaccinium ashei Reade) blueberry production has steadily grown from less than 300 commercial acres in 1976 to $\approx 15,000$ commercial acres in 2006 in the southeast United States (Texas, Louisiana, Mississippi, Alabama, Georgia, and Florida) (Braswell, pers. comm.) and acreage devoted to rabbiteye blueberries continues to expand.

Although rabbiteye blueberries are the predominant type of blueberry grown commercially in the region, acreage devoted to the recently introduced southern highbush blueberry is also increasing. Southern highbush ( $V$. corymbosum) blueberries generally ripen earlier than rabbiteye blueberries and better fit the more lucrative early fresh market window. Yet, southern highbush and rabbiteye blueberry cultivars are susceptible to rain-induced splitting, but the severity differs among cultivars (Marshall et al., 2002). A 2006 survey of blueberry growers in Mississippi and Louisiana indicated fruit splitting reduces marketable fruit and thus profit by $14 \%$ to $30 \%$ (Marshall et al., 2006). This results in a $\$ 300$ to $\$ 500$ per acre loss resulting from split fruit.

Splitting occurs more frequently if the plants receive a large amount of rainfall just before harvest. Additionally, droughtstressed rabbiteye blueberries are more likely to sustain rain-related splitting (Austin, 1994; Lyrene and Crocker, 1991; Rooks et al., 1995). Water absorbed through the epidermis of the skin as well as from the roots contributes to splitting. Marshall (2001) found that protecting plants from rain reaching and resting on the fruit was not sufficient to

Received for publication 29 Oct. 2007. Accepted for publication 27 Nov. 2007.

${ }^{1}$ To whom reprint requests should be addressed; e-mail DAMarshall@msa-stoneville.ars.usda.gov eliminate splitting. Grower observations suggest that fruit on plants often irrigated with overhead irrigation are less likely to split than those that are irrigated with drip irrigation (Hutto, pers. comm.). This is true of cherries as well (Ackley and Krueger, 1980). Splits in blueberries are usually oblong wounds in the fruit skin that may range from a small, shallow crack in the skin alone or, more commonly, deep wounds that penetrate into the fruit pulp. Deeper wounds suggest splitting not only occurs at the epidermis, but can begin deep within the fruit as well.

The cause of rain-induced splitting in sweet cherries, tomatoes, and grapes has been researched extensively. Factors contributing to splitting in cherries include cultivar differences, water temperature, period of wetting, soluble solids, fruit firmness and turgor, and elasticity of the skin (Ackley and Krueger, 1980; Bullock, 1952; Davenport et al., 1972a; Gerhardt et al., 1945; Marshall, 1954; Powers and Bollen, 1947; Zielinski, 1964). Ultimately, absorption of external water through the fruit skin has directly or indirectly been demonstrated to cause cracking in cherries (Ackley and Krueger, 1980; Andersen and Richardson, 1982; Bullock, 1952; Davenport et al., 1972b; Zielinski, 1964).

If key factors related to fruit splitting in blueberries can be identified and evaluated before release of potential new cultivars, then long-term reductions in commercial blueberry fruit splitting are possible. Some cultivars such as 'Tifblue' (rabbiteye) and 'Pearl River' (pentaploid) are especially susceptible to rain-related splitting, whereas other cultivars such as 'Premier' (rabbiteye) and 'Magnolia' (southern highbush) are seemingly resistant to splitting (Marshall et al., 2002). When comparing postharvest quality for three of the more common rabbiteye blueberries in commercial production ('Tifblue',
'Premier', and 'Climax'), Marroquin-Rosada (1994) found that 'Tifblue' (higher incidence of splitting) has a tougher skin and requires more force to compress and sheer the fruit than does 'Premier' (resistant to splitting). These findings suggest that cultivars with firmer fruit were more susceptible to splitting. This and other studies have tested only a limited number of cultivars. Therefore, the current study was initiated to further investigate the correlation between splitting susceptibility and fruit firmness on a wider array of blueberry cultivars and accessions to establish if fruit firmness could predict fruit splitting tendencies.

\section{Materials and Methods}

\section{Laboratory-induced splitting}

Both subsequent studies used a laboratory estimation of rain-induced splitting using a method developed by Marshall et al. (2007). Briefly, fruit with no visible tears were placed into beakers and filled with distilled water to simulate conditions similar to that of a significant period of exposure to rainwater. A smaller beaker was placed on top of the fruit to ensure that floating fruit were completely submerged. Beakers were left on the countertop in the laboratory at room temperature $\left(25^{\circ} \mathrm{C}\right)$ for $14 \mathrm{~h}$. Fruit were then drained and berries examined for splitting. Berries with a visible tear $1 \mathrm{~mm}$ or longer in the cuticle were considered split. Berry used in laboratory-induced splitting tendency tests were not presubjected to any other tests.

\section{Study 1: Field survey (rabbiteye} and southern highbush), 2001

A field survey was taken in 2001 on 14 rabbiteye and six southern highbush cultivars and selections. Blueberries surveyed for splitting tendencies and quality were grown in the USDA-ARS, Thad Cochran Southern Horticultural Laboratory's (SHL) research plantings in Poplarville and Stone County, MS. Bulk samples of fruit $(\approx 1.4 \mathrm{~L})$ were harvested from mature cultivars planted in a completely random design with four oneplant replications of each cultivar/selection. Plants were grown according to commercial practices recommended for this area (Spiers et al., 1985). Berries were harvested 15 May to 20 June with the exact dates determined by commercial ripeness. In all laboratory measurements, berries were randomly selected from the bulk samples.

Splitting tendencies. Four replications of 40 fruit were subjected to the laboratoryinduced splitting test. The number of split fruit was counted and percent splitting was calculated.

Firmness. Within the same subsamples of fruit, four replications of 15 berries were subjected to firmness measurements using a QTS25 Texture analyzer (StevensMetric, Middleboro, MA). The QTS25 was equipped with a steel ball probe and was programmed to deliver $5.0 \mathrm{~g}$ of force. Berry modulus of elasticity and deformation values were obtained. Modulus of elasticity is measured 
as the stiffness of a given material. It is calculated from the ratio of the rate of change of stress with strain $(\mathrm{g} \cdot \mathrm{s})$ determined from the slope of a stress-strain curve. Deformation is the distance covered compressing a sample and is measured in millimeters. Modulus and deformation values were correlated to percent berry splitting calculated from laboratory tests. Correlations were analyzed by Pearson's correlation coefficient using SAS (SAS Institute, 2001).

\section{Study 2: Rabbiteye variety planting}

At the SHL research plantings in Poplarville, MS, 12 rabbiteye varieties were planted in Mar. 2005 in a randomized complete block design with four replications of two plants/ plot. In the summer of 2006, all fruit were picked at ripeness and analyzed for splitting and firmness. Fifty berries from each plot were subjected to laboratory-induced splitting, whereas 20 berries from each plot were analyzed for firmness. In this study, a FirmTech2 (Timm et al., 1996) fruit firmness tester (BioWorks, Inc., Wamego, KS) was used instead of the QTS25. The minimum force was set at $25 \mathrm{~g}$ and the maximum force was set at $300 \mathrm{~g}$. Firmness values were correlated to the splitting percents calculated from the splitting test. Data were analyzed by analysis of variance and Pearson's correlation coefficient using SAS (SAS Institute, 2001).

\section{Results and Discussion}

Study 1. Splitting percentages ranged from 55.6\% in 'Pearl River' to $0.0 \%$ in 'Magnolia' and 'MS614' (Table 1). As found in previous studies 'Tifblue' had a greater incidence of splitting (28.1\%) than did 'Premier' $(10.6 \%)$. Modulus of elasticity values ranged from $36.431 \mathrm{~g} \cdot \mathrm{s}^{-1}$ in 'MS 614' to $14.526 \mathrm{~g} \cdot \mathrm{s}^{-1}$ in 'Premier'. Deformation values were highest in 'Premier' $2.502 \mathrm{~mm}$ and lowest in 'MS614' with $1.020 \mathrm{~mm}$. There was a significant negative correlation between laboratory splitting percentages and deformation values measured on the QTS25 texture analyzer (Table 2) when considering all 20 cultivars. As the deformation length decreased, splitting percentages increased. This suggests that firmer berries tend to have a higher splitting tendency. Yet, splitting did not correlate to modulus of elasticity measurement, which is a measure of stiffness.

A scatterplot of the splitting and deformation data (Fig. 1) and splitting versus modulus of elasticity data (Fig. 2) shows a trend with four points outlying the grouping. These four points belong to 'MS614'. 'MS614' exhibited the highest modulus of elasticity value of $36.43 \mathrm{~g} \cdot \mathrm{s}^{-1}$, but also exhibited the lowest percentage of splitting $(0 \%)$. When this one outlier was removed from the data set (Table 2), the correlation between splitting and modulus of elasticity increased from 0.12124, which was not significant, to 0.33436 , which was highly significant $(P=0.007)$. Likewise, the deformation value increases from -0.24222

Table 1. Splitting tendencies as determined by laboratory-induced splitting technique and firmness measurements obtained from QTS25 instrument.

\begin{tabular}{lccc}
\hline Cultivar & Split (\%) & $\begin{array}{c}\text { Modulus of } \\
\text { elasticity }(\mathrm{g} \cdot \mathrm{s})\end{array}$ & Deformation (mm) \\
\hline MS 614 (RE) & $0.0 \mathrm{~g}$ & $36.431 \mathrm{a}$ & $1.020 \mathrm{i}$ \\
Magnolia (SHB) & $0.0 \mathrm{~g}$ & $18.416 \mathrm{gh}$ & $2.228 \mathrm{bc}$ \\
Austin (RE) & $2.5 \mathrm{fg}$ & $21.307 \mathrm{def}$ & $1.923 \mathrm{de}$ \\
MS 157 (SHB) & $2.5 \mathrm{fg}$ & $16.250 \mathrm{hi}$ & $2.361 \mathrm{ab}$ \\
Jubilee (SHB) & $5.6 \mathrm{efg}$ & $22.046 \mathrm{def}$ & $1.734 \mathrm{efgh}$ \\
Brightwell (RE) & $6.9 \mathrm{efg}$ & $19.332 \mathrm{fg}$ & $2.092 \mathrm{~cd}$ \\
MS 635 (RE) & $6.9 \mathrm{efg}$ & $23.795 \mathrm{~cd}$ & $1.606 \mathrm{fgh}$ \\
MS 516 (RE) & $7.5 \mathrm{efg}$ & $20.701 \mathrm{efg}$ & $1.896 \mathrm{de}$ \\
Premier (RE) & $10.6 \mathrm{def}$ & $14.526 \mathrm{i}$ & $2.502 \mathrm{a}$ \\
MS 590 (RE) & $11.3 \mathrm{de}$ & $25.140 \mathrm{bc}$ & $1.500 \mathrm{gh}$ \\
MS 524 (RE) & $11.9 \mathrm{de}$ & $15.620 \mathrm{i}$ & $2.467 \mathrm{ab}$ \\
Gulf Coast (SHB) & $12.5 \mathrm{de}$ & $15.839 \mathrm{i}$ & $2.431 \mathrm{ab}$ \\
MS 3204 (RE) & $12.5 \mathrm{de}$ & $26.830 \mathrm{~b}$ & $1.469 \mathrm{~h}$ \\
MS 7 (SHB) & $13.8 \mathrm{de}$ & $19.396 \mathrm{fg}$ & $1.904 \mathrm{de}$ \\
Beckyblue (RE) & $17.5 \mathrm{~d}$ & $23.134 \mathrm{cde}$ & $1.764 \mathrm{efg}$ \\
Chaucer (RE) & $17.5 \mathrm{~d}$ & $25.814 \mathrm{bc}$ & $1.557 \mathrm{fgh}$ \\
MS 535 (RE) & $18.1 \mathrm{~d}$ & $18.600 \mathrm{gh}$ & $2.062 \mathrm{~cd}$ \\
Tifblue (RE) & $28.1 \mathrm{c}$ & $21.689 \mathrm{def}$ & $1.778 \mathrm{ef}$ \\
Climax (RE) & $40.6 \mathrm{~b}$ & $24.075 \mathrm{~cd}$ & $1.573 \mathrm{fgh}$ \\
Pearl River (Pentaploid) & $55.6 \mathrm{a}$ & $23.426 \mathrm{cde}$ & $1.674 \mathrm{efgh}$ \\
CoVar & 35.67 & 8.82 & 9.33 \\
\hline
\end{tabular}

Mean separation within columns. Mean with different letter indicate significance at $P<0.05$ level.

Table 2. Pearson's correlation coefficients $(\mathrm{N}=100)$ values for splitting percentage and fruit firmness measurements of modulus of elasticity and deformation, 2001.

\begin{tabular}{|c|c|c|c|c|c|c|}
\hline & \multicolumn{2}{|c|}{ All varieties } & \multicolumn{2}{|c|}{ Removed MS614 } & \multicolumn{2}{|c|}{$\begin{array}{l}\text { Seven varieties known for } \\
\text { splitting tendency }\end{array}$} \\
\hline & Modulus & Deformation & Modulus & Deformation & Modulus & Deformation \\
\hline Split & 0.12124 & -0.242 & 0.33436 & -0.384 & 0.551 & -0.583 \\
\hline Modulus & 0.2202 & $\begin{array}{l}0.0132 \\
-0.958 \\
<0.001\end{array}$ & 0.0007 & $\begin{array}{l}<0.007 \\
-0.979 \\
<0.001\end{array}$ & $<0.001$ & $\begin{array}{l}<0.001 \\
-0.974 \\
<0.001\end{array}$ \\
\hline
\end{tabular}

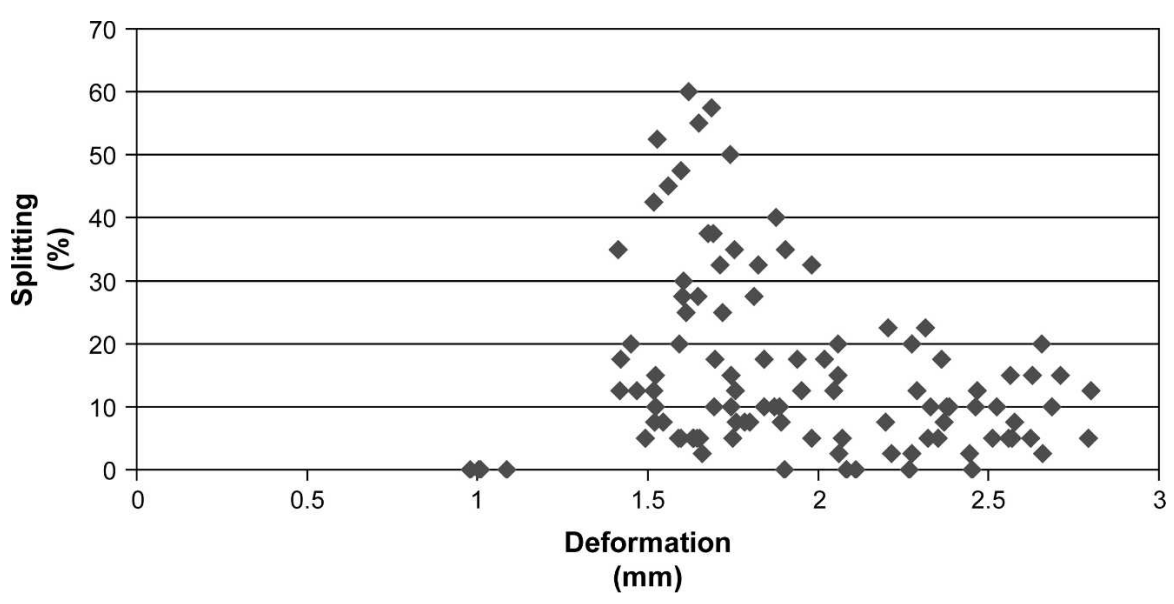

Fig. 1. Scatterplot for correlation between percent splitting and firmness values found on blueberry varieties and selections harvested, 2001. Correlation $-0.24222 . \mathrm{n}=80$.

$(P=0.0132)$ to $-0.38366(P=0.007)$ when 'MS614' is removed from the data set. Removal of the outlier greatly increases the significance and strength of the correlation. Furthermore, when the data set was restricted to seven cultivars known for their natural rain-related splitting tendencies ('Tifblue', 'Premier', 'Climax', 'Brightwell', 'Jubilee', 'Magnolia', 'Pearl River,'), the correlations of splitting to deformation $(-0.58312 ; P<$
$0.001)$ and modulus of elasticity $(0.55090$; $P<0.001)$ values increased further. This gives confidence to the test of splitting tendencies and its relationship to firmness values.

Study 2. When fruit firmness was measured on FirmTech2, no significant correlation was found between splitting percentages and firmness (Figs. 3 and 4). Figure 4 depicts the relationships between splitting and firmness for each cultivar. In this study, fewer 


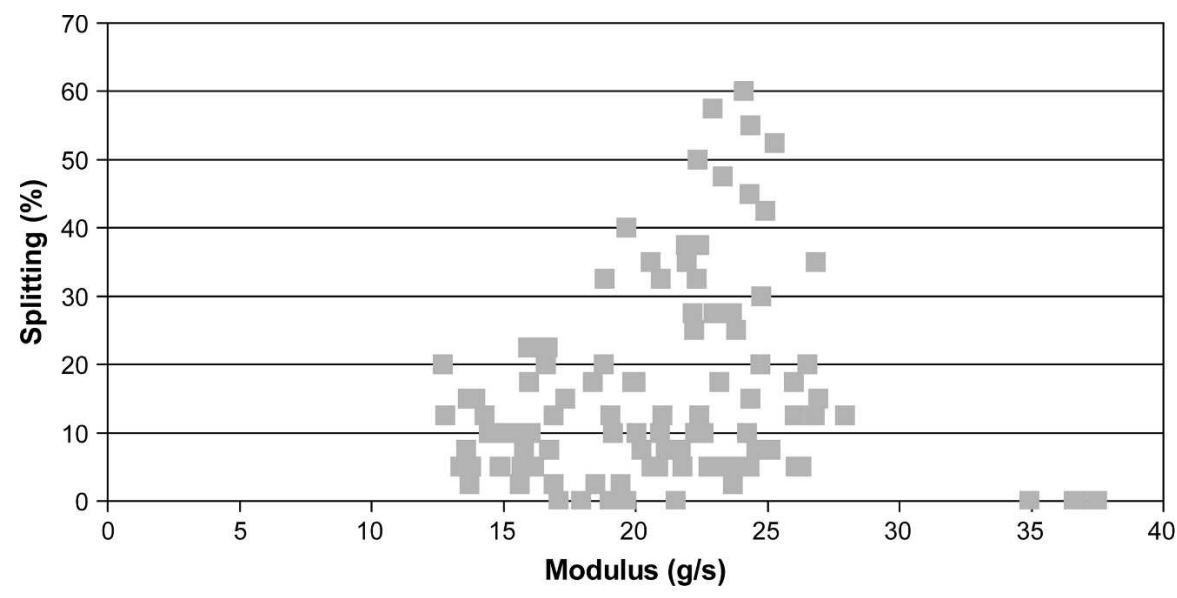

Fig. 2. Scatter plot for correlation between percent splitting and modulus of elasticity values found on blueberry varieties and selections harvested, 2001. Correlation $0.12124 . \mathrm{n}=80$.

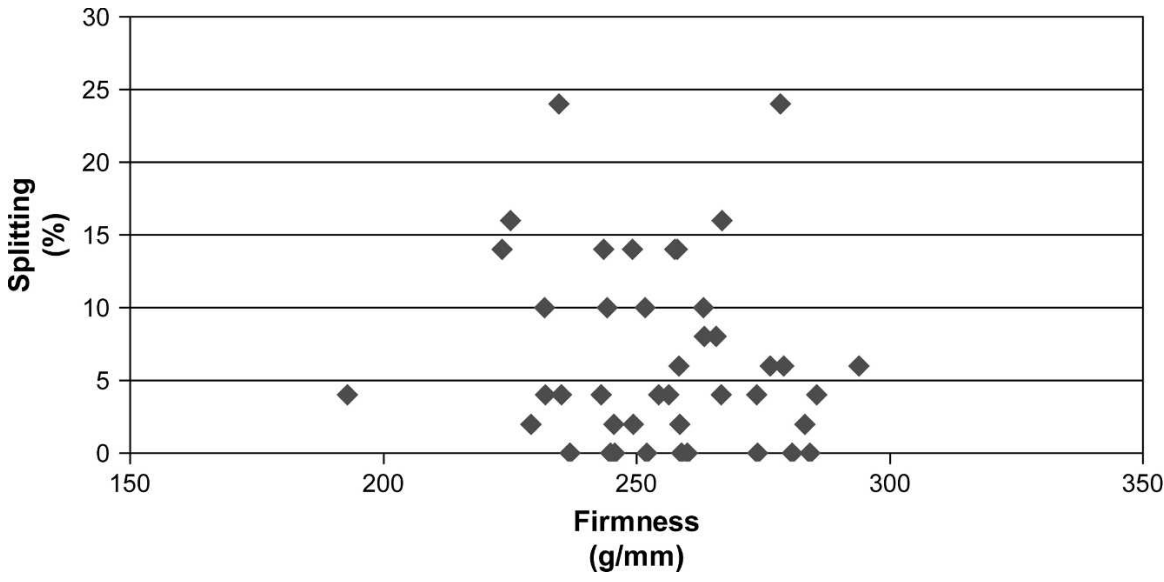

Fig. 3. Scatterplot for correlation between percent splitting and firmness values obtained from FirmTech2 found on blueberry cultivars harvested, 2006. Correlation $=-0.021059 . \mathrm{n}=48$.

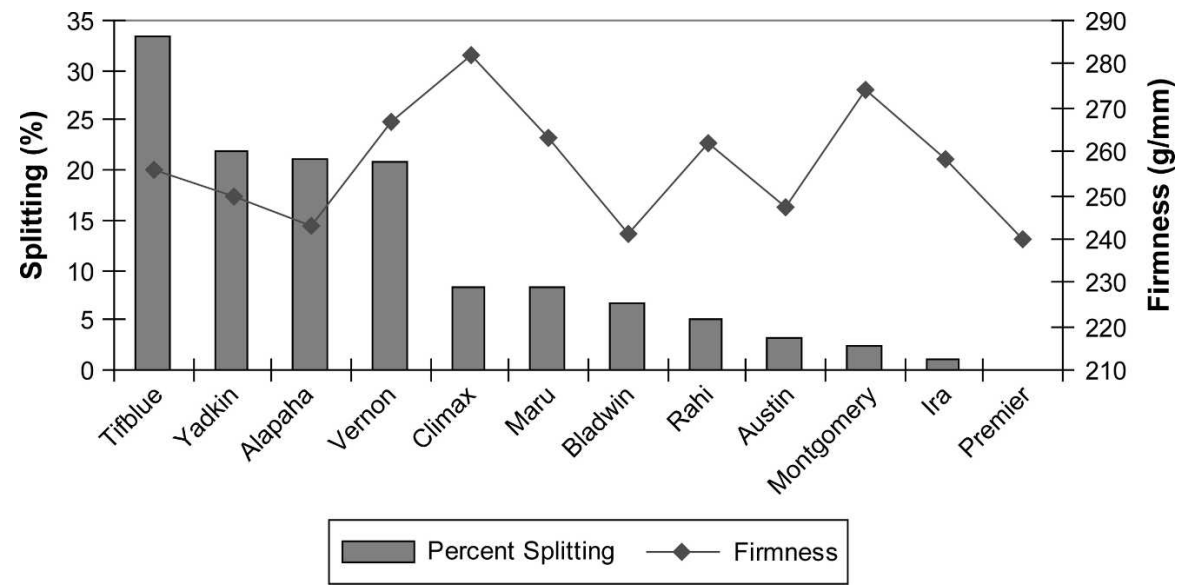

Fig. 4. Rabbiteye varieties splitting indices and firmness measurements obtained from FirmTech2, 2006.

cultivars were studied. Yet no significant correlation was seen.

\section{Conclusion}

Fruit firmness can be a predictor of fruit splitting if measured as deformation using the QTS25. No significant correlations were found with splitting tendencies and firmness values measured as modulus of elasticity (stiffness) using the QTS25. In this study, there was one ('MS614') selection that was extremely firm as measured by QTS25 deformation and modulus of elasticity and was also very resistant to laboratory-induced splitting $(0 \%)$. When this outlying selection was removed, the significance of both deformation and modulus of elasticity correlations to splitting became highly significant. An even stronger correlation was found when data were restricted to cultivars that are known for natural splitting tendencies. No correlation was found between splitting tendencies and firmness as measured on FirmTech2 suggesting although fewer cultivars were tested, FirmTech2 is not a good indicator of fruit splitting. This instrument is better suited for routine fruit firmness determination and is well equipped for such use with automated capacity for large samples.

In selecting blueberry progeny for advancement in breeding programs, geneticists use a variety of measurements to determine quality of the fruit. Firmness values are useful for determining fruit suitability for mechanical harvesting and long-distance shipping (NeSmith, 2007). This study used two instruments for measuring firmness. The FirmTech2 seems to be better suited for measuring shipping resistance. Yet firmness measured as deformation or modulus of elasticity with the QTS25 is best for predicting splitting tendencies for most cultivars. In general, firmer fruit will have a higher tendency for splitting. This suggests that if geneticists select for the favorable trait of very firm fruit, they may also be selecting for the negative trait of splitting tendency (NeSmith, 2007). Nevertheless, the one outlying selection ('MS614') exhibiting extreme firmness and splitting resistance has the fruit characteristics that are very desirable to cultivar release for commercial production and would be a very good berry for mechanically harvesting in humid climates. This selection would have been discarded if firmness values alone were used to denote splitting indicating that regardless of firmness values, a laboratory test to determine splitting susceptibility would be beneficial to geneticists as a truer indicator of germplasm splitting tendencies.

\section{Literature Cited}

Ackley, W.B. and W.H. Krueger. 1980. Overhead irrigation water quality and the cracking of sweet cherries. HortScience 15:289-290.

Andersen, P.C. and D.G. Richardson. 1982. A rapid method to estimate fruit water status with special reference to rain cracking of sweet cherries. J. Amer. Soc. Hort. Sci. 107:441-444.

Austin, M. 1994. Rabbiteye blueberries, p. 20-21. Agscience, Inc., Auburndale, FL.

Bullock, R.M. 1952. A study of some inorganic compounds and growth promoting chemicals in relation to fruit cracking of Bing cherries at maturity. Proc. Amer. Cos. Hort. Sci. 59:243253.

Davenport, D.C., M.A. Fisher, and R.M. Hagen. 1972a. Some counter active effects of antitranspirants. Plant Physiol. 49:722-724.

Davenport, D.C., K. Uriu, and R.M. Hagen. 1972b. Antitranspirant film: Curtailing intake of external water by cherry fruit to reduce cracking. HortScience 7:507-508.

Gerhardt, F., H. English, and E. Smith. 1945. Cracking and decay of Bing cherries as related to the presence of moisture on the surface of the fruit. Proc. Amer. Soc. Hort. Sci. 46:191-198. 
Lyrene, P.M. and T.E. Crocker. 1991. Commercial blueberry production in Florida. IFAS, Gainesville.

Marroquin-Rosada, E. 1994. Physiochemical and microstructural properties of fresh highbush and rabbiteye blueberries, their physiochemical changes during refrigerated storage, and method for softening frozen rabbiteye berries, Mississippi State University, PhD Diss.

Marshall, D.A. 2001. Physiological differences contributing to the incidence of splitting in 'Premier' and 'Tifblue' rabbiteye blueberries (Vaccinium ashei Reade). University of Southern Mississippi, PhD Thesis.

Marshall, D.A., J.M. Spiers, and J.H. Braswell. 2006. Splitting severity among rabbiteye (Vaccinium ashei Reade) blueberry cultivars in Mississippi and Louisiana. Intl. J. Fruit Sci. 6:77-81.
Marshall, D.A., M.J Spiers, and K.J. Curry. 2002. Incidence of splitting in 'Premier' and 'Tifblue' rabbiteye blueberries. In: Hepp, R.F. (ed.). Proc. 7th International Symposium on Vaccinium. Acta Hort. 574:295-303.

Marshall, D.A., J.M. Spiers, K.J. Curry, and S.J. Stringer. 2007. Laboratory method to estimate rain-induced splitting in cultivated blueberries HortScience 42:1551-1553.

Marshall, R.E. 1954. Cherries and cherry products. Interscience Publishers, Inc., New York, p. 6063.

NeSmith, D.S. 2007. Evaluation of fruit cracking and berry firmness in rabbiteye blueberry. HortScience 42:457.

Powers, W.L. and W.B. Bollen. 1947. Control of cracking of fruit by rain. Science 105:334-335.
Rooks, S.D., J.R. Ballington, and C.M. Mainland. 1995. 'Bladen' southern highbush blueberry. HortScience 30:150-151

SAS Institute. 2001. SAS/STAT user's guide. Ver. 8.2. SAS Inst., Cary, NC.

Spiers, J.M., J.H. Braswell, and C.P. Hegwood Jr. 1985. Establishment and maintenance of rabbiteye blueberries. MS Agr. and For. Exp. Sta., Bul. 941:12

Timm, E.J., G.K. Brown, P.R. Armstrong, R.M Beaudry, and A. Shirazi. 1996. Portable instrument for measuring firmness of cherries and berries. Appl. Eng. Agr. 12:71-77.

Zielinski, Q.B. 1964. Resistance of sweet cherry varieties to fruit cracking in relation to fruit and pit size and fruit color. Proc. Amer. Soc. Hort. Sci. 84:98-102. 